\title{
Pre-clinical investigation of the synergy effect of interleukin-12 gene-electro- transfer during partially irreversible electropermeabilization against melanoma
}

Lise Pasquet, Elisabeth Bellard, Sophie Chabot, Bostjan Markelc, Marie-Pierre Rols, Justin Teissie* and Muriel Golzio* (1)

\begin{abstract}
Background: Melanoma is a very aggressive skin tumor that can be cured when diagnosed and treated in its early stages. However, at the time of identification, the tumor is frequently in a metastatic stage. Intensive research is currently ongoing to improve the efficacy of the immune system in eliminating cancer cells. One approach is to boost the activation of cytotoxic T cells by IL-12 cytokine that plays a central role in the activation of the immune system. In parallel, physical methods such as electropermeabilization-based treatments are currently under investigation and show promising results.

Methods: In this study, we set electrical parameters to induce a partial-irreversible electropermeabilization (pIRE) of melanoma to induce a sufficient cell death and potential release of tumor antigens able to activate immune cells. This protocol mimics the situation where irreversible electropermeabilization is not fully completed. Then, a peritumoral plasmid IL-12 electrotransfer was combined with pIRE treatment. Evaluation of the tumor growth and survival was performed in mouse strains having a different immunological background (C57Bl/6 (WT), nude and C57Bl6 (TLR9-/-)).

Results: pIRE treatment induced apoptotic cell death and a temporary tumor growth delay in all mouse strains. In C57BI/6 mice, we showed that peritumoral plasmid IL-12 electrotransfer combined with tumor pIRE treatment induced tumor regression correlating with a local secretion of IL-12 and IFN- $\gamma$. This combined treatment induced a growth delay of distant tumors and prevented the emergence of a second tumor in 50\% of immunocompetent mice.

Conclusions: The combination of plL-12 GET and pIRE not only enhanced survival but could bring a curative effect in wild type mice. This two-step treatment, named Immune-Gene Electro-Therapy (IGET), led to a systemic activation of the adaptive immune system and the development of an anti-tumor immune memory.
\end{abstract}

Keywords: Gene electrotransfer, Melanoma, Electroporation, IL-12, Immunotherapy

\footnotetext{
* Correspondence: justin.teissie@ipbs.fr; muriel.golzio@ipbs.fr

Institut de Pharmacologie et de Biologie Structurale, Université de Toulouse, CNRS, UPS, BP 64182, UMR 5089, 205 Route de Narbonne, F-31077 Toulouse Cedex, France
}

(c) The Author(s). 2019 Open Access This article is distributed under the terms of the Creative Commons Attribution 4.0 International License (http://creativecommons.org/licenses/by/4.0/), which permits unrestricted use, distribution, and reproduction in any medium, provided you give appropriate credit to the original author(s) and the source, provide a link to the Creative Commons license, and indicate if changes were made. The Creative Commons Public Domain Dedication waiver (http://creativecommons.org/publicdomain/zero/1.0/) applies to the data made available in this article, unless otherwise stated. 


\section{Background}

Early diagnosis and treatment of melanoma is essential to cure this aggressive skin tumor. However, the tumor is frequently already metastatic when identified. In this case, even though several treatments are available, the probability for a complete remission are dramatically decreased. Intensive research is currently ongoing to improve the efficacy of the immune system in eliminating cancer cells. One approach consists in blocking the negative regulation of the immune system with checkpoint inhibitor antibodies that block PD1/PDL-1 and/or CTLA-4 immune checkpoints [1]. An alternative approach is boosting the activation of cytotoxic T cells (CTL).

The cytokine interleukin 12 (IL-12) plays a central role in the activation of the immune system [2]. Produced by dendritic cells (DC), macrophages and neutrophils, IL-12 induces the production of interferon $\gamma$ (INF $\gamma$ ) by activated $\mathrm{T}$ cells and NK cells. Moreover, IL-12 induces a positive feedback on its own secretion. Indeed, IL-12-induced IFN $\gamma$ secretion by CTL and type I helper CD4 T cells (Th1) acts back on DC's to reinforce their secretion of IL12 [2]. Therefore, IL-12 has appeared as a key molecule to enhance the anti-tumor immune response. However, as the sustained positive feedback loop induced by recombinant IL-12 administration could lead to high toxicity [3], it is crucial, in the context of IL-12 based therapy, to control the availability of this cytokine in vivo. This can be achieved by gene therapy, which consists in the transfer of DNA coding for IL-12 into appropriate target cells. Use of viral vectors, such as lentivirus, lead to a high transduction rate, but display random integration capacities thus hampering their usability for in vivo transfection. Among nonviral methods, Gene-Electro-Therapy (GET) is a promising physical method that brings a controlled level of transfection [4-6]. In vitro, the application of well-defined electric pulses to target cells promotes the entrance of the negatively charged plasmid DNA into the cell resulting in transgene expression [7]. A phase I clinical trial showed that intratumoral GET of plasmid DNA encoding IL-12 (IL-12 GET) resulted in complete regression of melanoma tumors in 2 patients and in a stable disease in 8 patients out of 19 [8]. This was associated with tumor cell necrosis and intratumoral secretion of IL-12. It has been reported that intratumoral GET induces the transfection of only $5 \%$ of targeted cells resulting in low levels of transgene expression [5], whereas peritumoral GET induces a better yield of transgene expression [9, 10]. Peritumoral GET, however, loses the advantage of a colocalization with tumor antigen release by lysed tumor cells upon application of electric field. Therefore, it appears that an efficient anti-tumor therapy based on cell electro-permeabilization (EP) should combine a high level of transgene expression with a maximum release of hidden tumor antigens while maintaining low side effects. Several studies using combination of electrochemotherapy and IL-12 gene electrotransfer demonstrated a high antitumor efficacy, also preventing recurrence of distant metastases [11, 12]. Numerous studies suggest involvement of innate and adaptive anti-tumor immune responses induced by IL-12 gene expression and the delivery of the chemotherapeutic agent [10, 13-15].

One method to achieve the release of hidden tumor antigens may be through a strong EP intensity that leads to cell death. This irreversible permeability induced by Electropermeabilization (IRE), is due to the inability of targeted cells to repair the bio-electro-chemical defects of the plasma membrane or the chemical imbalances that occur due to influx and efflux of molecules through these transient or stable defects [16]. These events occur in targeted cells between paired electrodes applied to tissue [17]. This technique has been extensively used for non-thermal ablation of tumors [18] and introduced as cancer treatment in the human clinic [19]. Mechanisms of IRE-induced-cell-death have been widely investigated looking at the cell morphology by histology as well as transmission and scanning electron microscopy [20-22]. The exact pathways required in IRE induced cell death remain under discussion, but it seems that several mechanisms are implicated according to pulsed electric field exposure [20, 23, 24]. In vivo, the effect of IRE has been observed at the tissue-level such as edema (induced by capillary-disruption), hypoxia (induced by temporary vascular occlusion) $[25,26]$ or possibly, the activation of immune system [27-29]. Importantly, the effect of IRE treatment was shown to be very localized. Tumor tissues treated with IRE exhibited a peak of apoptotic cell death at $24 \mathrm{~h}$ after IRE, whereas tissue around the treated area was not affected [30]. In liver and pancreas, IRE treatment was shown to have an anti-tumor effect while still preserving the integrity and function of bile conducts and blood vessels, inducing a slight and transient effect on concentrations of liver and pancreas enzymes [26, 31]. This ability of IRE to achieve cell death immediately adjacent to large vessels without affecting the vessels or peri-ablative tissues made IRE a promising and safe targeted treatment for cancer without drug usage. However, care must be taken in IRE protocols, by carefully choosing pulsed electric field (PEF) parameters to achieve a predominant cell death due to electropermeabilization. Too many pulses and/or a too high tissue conductivity are reported to lead to thermal damages in the immediate vicinity of the electrodes [32]. Furthermore, thermal effects induced by clinical IRE protocols using high energy regimens are reported to moderate the effects of IRE non-thermal ablation [33]. Boosting the IRE induced immune activation was also proposed [27-29].

In this study, we first set PEF parameters to induce a partial-irreversible electropermeabilization (pIRE) of 
melanoma without using cytotoxic agents. This setting led to cell death and potential release of tumor antigens able of activating the immune system. Our protocol mimicked the situation where irreversible electropermeabilization did not bring a complete eradication of the tumor. The set PEF parameters only induced in vivo partial cell death in the tumor, leading to a delay in tumor growth compared to untreated mice. In addition, we also studied the kinetics of apoptotic tumor cell death induced by PEF treatment. No thermal side effects were observed as demonstrated by the low activation of the thermo-inducible heat-shock protein (Hsp70) promoter 1B (Hspa1b), in double transgenic Hspa1b-LucF (+/+) Hspalb-mPlum (+/+) mice. Our pIRE treatment was then combined with peri-tumoral IL12 GET pre-treatment that was shown to induce a local and rapid production of IL-12 [10,34] and resulted in a rapid production of IFN $\gamma$. This treatment induced (i) an increased survival rate of treated animals, (ii) a systemic activation of the adaptive immune system leading to a growth delay of distant tumors and (iii) the development of immune memory that protected against the emergence of a second tumor. We could also discriminate the effect on the tumor growth between the application of peri-tumoral IL12 GET, pIRE, and the combination of both treatments.

\section{Methods}

\section{Cell lines}

B16F10 mouse melanoma (ATCC, Manassas, VA) and B16F10 cells expressing the enhanced Green Fluorescent Protein (B16F10-eGFP) [35], were grown as monolayer cultures on T75 flasks (Nunc, Denmark) at $37^{\circ} \mathrm{C}, 5 \%$ $\mathrm{CO}_{2}$ atmosphere in a humidified chamber until they reached $70 \%$ confluence. Culture medium used was Dulbecco's Modified Eagle Medium with $4.5 \mathrm{~g} / \mathrm{l} \mathrm{D}$-Glucose and L-Glutamine (DMEM; Gibco/ Life Technologies) supplemented with $10 \%$ fetal bovine serum (Sigma-Aldrich, St Louis, MO) and the antibiotics penicillin (100 $\mathrm{U} / \mathrm{ml})$ and streptomycin $(100 \mathrm{U} / \mathrm{ml})$ (Gibco/ Life Technologies).

\section{Mice}

Female C57Bl/6 mice, 6-7 weeks old and weighing 20$25 \mathrm{~g}$ were obtained from Janvier Labs (Le Genest St. Isle, France). C57Bl/6-CD11c-GFP-DTR, C57Bl/6-Lang-GFP mice (a generous gift of Dr. B. Malissen, CIML, Marseille, France) and TLR9 ${ }^{-1-}$ mice (gift from Invivogen, Toulouse, France) were bred in our animal facility. Nude mice were purchased from Charles River Laboratories France (L'Arbresle, France). Hspalb-LucF $(+/+)$ Hspa1b-mPlum $(+/+)$ mice were obtained from F. Couillaud (EA7435, Université de Bordeaux, France). Hspa1bLucF $(+/+)$ Hspa1b-mPlum $(+/+)$ mice contained a transgene that allowed firefly luciferase and mPlum fluorescent protein expression under the control of thermo-inducible heat-shock protein (Hsp70) promoter 1B (Hspa1b) [36]. All experiments involving animals were approved by the ethic committee (n'APAFIS\#42682016022516345743v2) and performed in compliance with relevant laws and institutional guidelines.

\section{Tumor model}

For tumor implantation, $0.5 \times 10^{6}$ B16F10 melanoma cells, in $20 \mu \mathrm{l}$ of PBS, were injected intradermally on the shaved flank of anesthetized mice. The injection was done using a $50 \mu \mathrm{L}$ Hamilton syringe (Hamilton $\mathrm{CH}-7402$ Bonaduz, GR. Switzerland) adapted with a 29G insulin needle. Tumors were detected 3 to 5 days after implantation and tumor growth was monitored every other day with a digital caliper. Tumor volume was determined by measuring the 3 dimensions of the tumor $(\mathrm{a}, \mathrm{b}, \mathrm{c})$ and using the following formula: Volume $\left(\mathrm{mm}^{3}\right)=(\pi / 6)^{*}\left(\mathrm{a}^{*} \mathrm{~b}^{*} \mathrm{c}\right)$. Mice bearing tumors reaching a volume greater than $1200 \mathrm{~mm}^{3}$ or necrotic tumors were sacrificed.

For the re-challenge, $0.5 \times 10^{6}$ B16F10 cells were injected intradermally as previously described on the opposite flank of the primary tumor.

To evaluate the systemic effect of the treatment, $0.5 \times$ $10^{6}$ B16F10 cells were injected intradermally the same day on both flanks of the animal. While one of the tumors was treated with IL-12 GET and pIRE the other tumor was left untreated. The size of both tumors was measured every day.

\section{pIRE treatment of tumor bearing mice}

Partially irreversible electropermeabilization (pIRE) was performed using the GHT Uni2000 from Beta Tech (Saint-Orens, France) connected to a digitized oscilloscope Gould (DSO)1602 (Gould, Ilford-Essex-UK). The pulse profiles were displayed and stored on the oscilloscope for an on-line control of the delivery. Tumors were treated using stainless steel, flat, parallel and 0.4 cm-gap electrodes (IGEA, Capri, Italy). The tumor was squeezed between the two plate electrodes using Echogel (Comepa, St Denis, France) to obtain a good electrical contact (See Additional file 1: Figure S1). pIRE conditions consisted of 10 square waved pulses of $1200 \mathrm{~V}$, duration $100 \mu \mathrm{s}$, delivered at a frequency of $1 \mathrm{kHz}$. High voltage and pulse duration used were classical values for IRE $[18,20]$. Only the number of pulses was reduced to obtain partial IRE. The use of $1 \mathrm{kHz}$ was preferred because of the shortened treatment duration inducing only one muscle contraction as already shown for ECT treatment [37]. Mice were gas-anesthetized with $2 \%(\mathrm{v} / \mathrm{v})$ of isoflurane and were kept under anesthesia during the whole procedure. Mice without EP served as control group for experiments. 


\section{In vivo fluorescence and color acquisitions of B16F10-} eGFP tumors

Visualization of B16F10-eGFP in vivo transfected cells was performed over several days after pIRE treatment using a Macrofluo microscope (Leica, Wetzlar, Germany) equipped with a cooled CCD camera (Roper Coolsnap HQ, Photometrics, Tucson, AZ). Animals were kept under isoflurane anesthesia during the observation. Color imaging was obtained by use of CRI Micro"Color 2 Liquid Crystal Technology. The fluorescence excitation was obtained with an EL6000 light source (Leica, Wetzlar, Germany) and the L5 $(\mathrm{ex}=480 / 40 \mathrm{~nm}, \mathrm{em}=527 / 30 \mathrm{~nm})$ filter set (Chroma technology, Rockingham, USA) for GFP observation. These images allowed analysis of tumor volume and GFP expression on the same animal during several days.

\section{Bioluminescence imaging and measurements}

The Hspalb-LucF (+/+) Hspalb-mPlum (+/+) mice allowed to follow up the induction of Hspalb promoter through the expression of luciferase reporter protein which could then be imaged with bioluminescence in vivo imaging.

Values for thermal stress positive control were determined between 39 and 45 degrees Celsius as already described [34] and luciferase activity was measured in the anesthetized animal using a cooled CCD camera (iKon $\mathrm{M}$, Andor, Belfast, UK) as a measure of reporter gene expression. Reporter gene expression was assessed at $6 \mathrm{~h}$ post-heating or pIRE treatment, $5 \mathrm{~min}$ after intraperitoneal injection of luciferin ( $3 \mathrm{mg} /$ mouse) in $100 \mu \mathrm{L}$ of PBS. Mean bioluminescence intensity in the treated area was determined using FIJI [34].

\section{Plasmid injection and gene-electro-transfer protocols}

GET treatment was performed as described in Pasquet et al. [34]. Briefly, tumor-surrounding skin was shaved and depilated using a depilatory cream the day prior treatment. When the B16F10 tumor volume reached 7 to $15 \mathrm{~mm}^{3}$, two injections of $25 \mu \mathrm{g}$ of IL-12 encoding pCpGfree-mIL-12 (p35p40) plasmid (pIL-12) in $20 \mu \mathrm{L}$ of PBS were performed in two distinct areas in the skin dermis directly surrounding the tumor (from 2 to $5 \mathrm{~mm}$ from the edge of the tumor). Stainless steel, contact electrodes $(0.4 \mathrm{~cm}$ gap) with Echogel were applied on the skin around the injection point. Four trains of squarewave unipolar High voltage-Medium voltage (HV-MV) pulses were applied using Electrocell B10 generator (Leroy Biotech, St Orens, France). Trains of HV pulses consisted of $100 \mu$ s square waved pulses of $400 \mathrm{~V}$. Trains of MV pulses consisted of $20 \mathrm{~ms}$ square waved pulses of $100 \mathrm{~V}$. The delay between each pulse was $50 \mathrm{~ms}$ and each pulse train was applied with a $1 \mathrm{~Hz}$ frequency. The proper delivery of the pulses was monitored live on a touch screen. In preliminary experiments, Il-12 transfection was performed $48 \mathrm{~h}$ before pIRE (pIRE + IL-12 T-
$48 \mathrm{~h}$ ), or the same day (pIRE + IL-12 T0 h) or $24 \mathrm{~h}$ after pIRE treatment ( $\mathrm{pIRE}+\mathrm{IL}-12 \mathrm{~T}+24 \mathrm{~h}$ ) (Additional file 2: Figure S2). The $48 \mathrm{~h}$ delay between GET and PIRE treatments was selected as the most effective in tumor total regression. (pIRE +IL-12 T-48 h.) (See Additional file 2: Figure S2).

\section{Histology}

Tumors were collected at $6 \mathrm{~h}$ and every day from 1 to 7 days after pIRE treatment. Samples were fixed in PLP buffer ( $0.05 \mathrm{M}$ phosphate buffer, $0.1 \mathrm{M}$ lysine, $2 \mathrm{mg} / \mathrm{ml}$ sodium periodate, $1 \%$ paraformaldehyde) for $24 \mathrm{~h}$. The day after, tissues were incubated $3 \mathrm{~h}$ in successive sucrose solutions $(10$, 20 and 30\%) and embedded in OCT. Five micrometer thick sections were cut, stained with hematoxylin-eosin (Sigma Aldrich, France) and mounted with Mowiol mounted medium. Observation was performed with a scanner reader (Pannoramic 250, 3DHISTECH).

\section{Apoptosis measurements}

Tumors were collected 24,48 and $72 \mathrm{~h}$ after pIRE treatment. Tumors were dissociated and single cell suspensions were labelled with Annexin V-FITC (OzymeBiolegend, St Quentin Yvelines, France) and 7AAD to evaluate the percentage of 7AAD negative and AnnexinV positive cells i.e. percentage of apoptotic cell death, by flow cytometry (FacsCalibur, BD Biosciences).

Determination of IFN $\gamma$ production in IL-12 GET treated skin Mice were treated with $2 x 25 \mu \mathrm{g}$ of IL-12 plasmid as described above. Control mice were injected with PBS and submitted to the same GET protocol. PBS GET and pIL12 GET treated areas, as well as contralateral skin, were clearly identified and harvested 1, 2, 3, 4, 7 and 14 days post-treatment. Samples were incubated in $2 \mathrm{~mL}$ complete culture medium at $37^{\circ} \mathrm{C}, 5 \% \mathrm{CO}_{2}$ for $24 \mathrm{~h}$.

IFN- $\gamma$ content in the culture supernatant was determined by ELISA according to the manufacturer protocol (ELISA MAX Deluxe Set, Biolegend, San Diego, CA).

\section{Toxicity tests}

pIL-12 GET toxicity was evaluated with hematology, biochemistry and anatomo-pathology results. The testing facility was C.RIS Pharma (Saint Malo, FRANCE) (Study No.: CP-2016029).

Two injections of $25 \mu \mathrm{g}$ of plasmid in $20 \mu \mathrm{L}$ of PBS were performed in two distinct areas in the dermis of the skin. Four trains of square-wave unipolar High voltage-Medium voltage (HV-MV) pulses were applied. Toxicity was performed at D15 and D49 after the GET.

Hematological parameters (white blood cells, hemoglobin, red blood cells, hematocrit, mean corpuscular volume, platelets, mean corpuscular hemoglobin, mean corpuscular hemoglobin concentration) were determined on 2 female 
and 2 male mice treated with control and 4 female and 3 male mice treated with GET sacrificed at D15 and on 2 female and 2 male mice treated with control and 4 female and 4 male mice treated with GET sacrificed at D49.

Biochemistry parameters (glucose, urea, creatinin, triglycerides, cholesterol, protein, albumin, GOT, GPT, calcium, phosphore, chloride, sodium, potassium, bilirubin) were determined on 2 female and 2 male mice treated with control and 4 female and 3 male mice treated with GET sacrificed at D15 and on 2 female and 2 male mice treated with control and 4 female and 4 male mice treated with GET sacrificed at D49.

\section{Statistical analysis}

Statistical analysis was carried out using Prism 5 statistical software (GraphPad Software Inc., San Diego, CA). Values are means \pm SEM. We used linear regression, 2way ANOVA t-test analysis. We used Log-rank (Mantel-Cox) test for survival curves.

\section{Results \\ pIRE parameters reduced tumor growth and increased survival}

In order to mimic the situation where irreversible electropermeabilization did not bring a complete eradication of the tumor, we first delivered PEF with parameters inducing a partial-irreversible electropermeabilization (pIRE) of melanoma. C57Bl/6 mice were intradermally injected with $0.5 \times$ $10^{6}$ B16F10-GFP cells and treated or not with pIRE parameters. Without any treatment, tumors had a fast growth rate and all mice had to be sacrificed maximum 16 days after tumor induction (Fig. 1). Compared to untreated tumors, pIRE treatment transiently reduced tumor size in the first five days after treatment inducing a delay in tumor growth (Fig. 1a and b). During this 5 days period, GFP fluorescence was not detectable in pIRE treated tumors showing a transient knock-down in cellular metabolism (Fig. 1a). Therefore, pIRE treatment significantly increased survival of mice compared to untreated mice (Fig. 1c). Similar delays in tumor growth and survival were obtained on different mouse strains (See Additional file 3: Figure. S3).

\section{pIRE treatment induced tumor cell death}

In order to characterize the effect of pIRE treatment on the tumor, we observed the microscopic evolution of treated tumors by histology 2 to 7 days after pIRE treatment (Fig. 2a). Treated and untreated tumors of identical initial volumes were collected 2, 3, 5 and 7 days after pIRE treatment and stained with hematoxylin and eosin. The size of treated tumors appeared significantly reduced 3 days after treatment compared to untreated tumors (Fig. 2a). Moreover, while untreated tumors grew quickly, the size of pIRE treated tumors remained overall stable from day 3 to 7 even though still measurable. The observation at a higher magnification 2 days after the treatment revealed a reduced cellularity in the treated tumors observable by the presence of "holes" inside the tumors (Fig. 2b). These blank areas were a proof of tumor cell death induced by pIRE treatment.

In order to better characterize the cellular events, we harvested treated tumors 6 to $72 \mathrm{~h}$ after treatment and stained the cells with Annexin $\mathrm{V}$ and AAD7 to distinguish apoptosis and necrosis pathways (Fig. 2c). A positive staining with 7AAD revealed a loss of cell membrane integrity, whereas the flip of phosphatidylserine, an early event characteristic of apoptosis, was identified by a solo Annexin V staining. Early apoptosis (Annexin V+l 7AAD-) was mostly present during two days after pIRE treatment showing a 2-fold increase of apoptotic cells relative to control tumors. At $72 \mathrm{~h}$ after treatment when the tumor size reached its minimum value, the percentage of apoptotic cells was not significantly different from control tumors.

\section{pIRE treatment did not induced any thermal side effects}

To study the role of thermal effect in pIRE induced tumor cell death, the pIRE procedure was applied on tumors implanted in Hspalb-LucF $(+/+)$ Hspalb-mPlum $(+/+)$ mice and followed by non-invasive bioluminescence imaging. A slight luminescent signal was observed in the treated zone. The positioning of the electrodes was visualized $6 \mathrm{~h}$ after treatment (See Additional file 4: Figure $\mathrm{S} 4 \mathrm{~A}$ ) and the mean bioluminescence intensity was quantified showing a significant increase when compared to untreated tumor (See Additional file 4: Figure S4B). The ratio of mean bioluminescence intensities between the treated and untreated areas showed a $1.6+/-0.3$ fold increase (See Additional file 4: Figure S4C). The corresponding increase of temperature in the treated zone was determined using a positive control for thermal stress and corresponded to the $8 \mathrm{~min}$ exposition of the control mice to $39-40^{\circ} \mathrm{C}$. (See Additional file 4: Figure S4D). This low temperature was the experimental evidence that pIRE treatment did not induce thermal side effect and that the pIRE induced tumor cell death was not due to a thermal process but was a consequence of the electroporation induced membrane disruption.

In conclusion, the PEF parameters we set induced a partially irreversible electroporation (PIRE) by causing apoptotic tumor cell death resulting in transient tumor regression. Importantly, this treatment did not induce immediate side effects. However, after 5 days, treated tumors seemed to grow at the same rate as untreated tumors suggesting no visible implication of the adaptive immune system. Nevertheless, hidden tumor antigens might have been released during the 

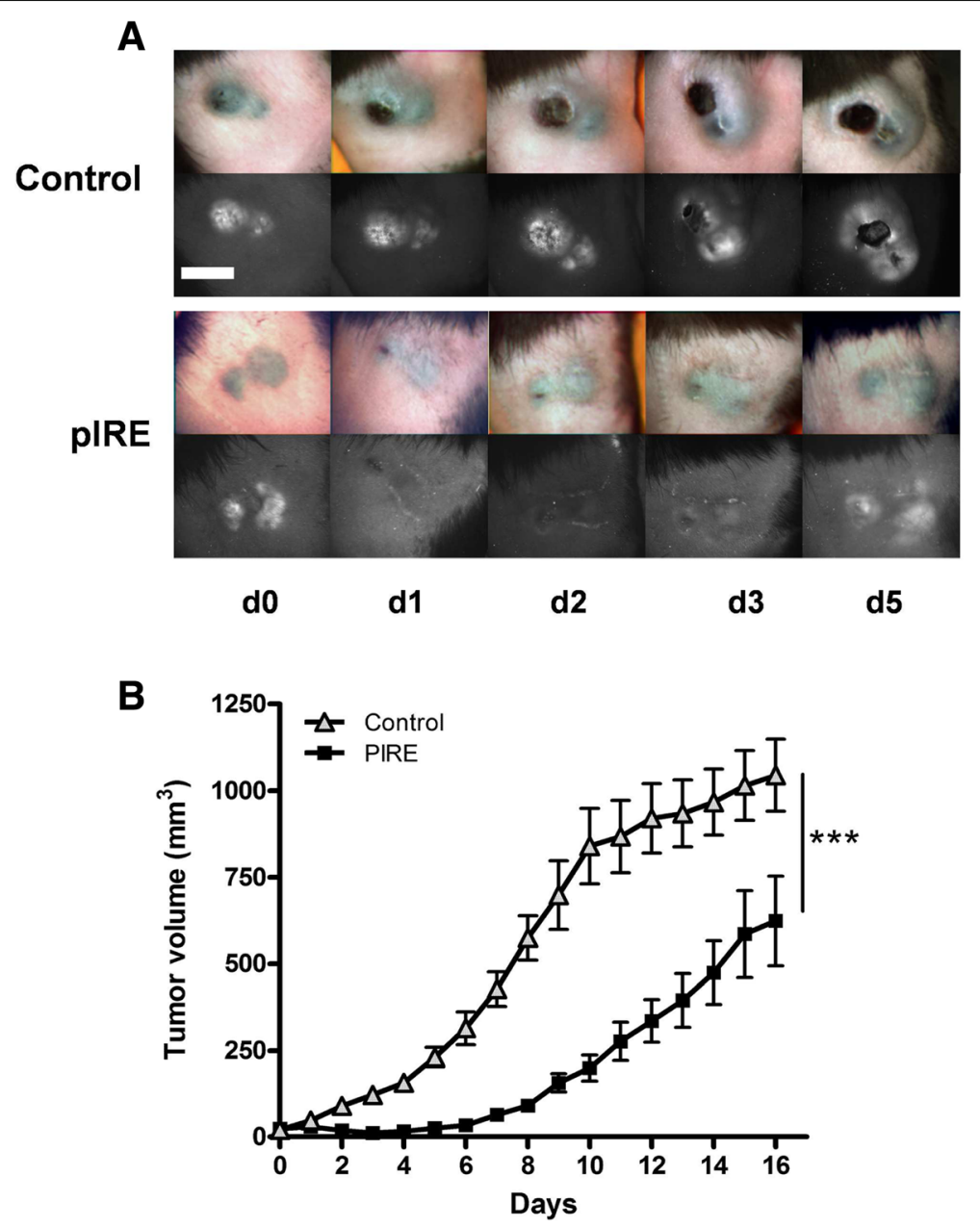

C

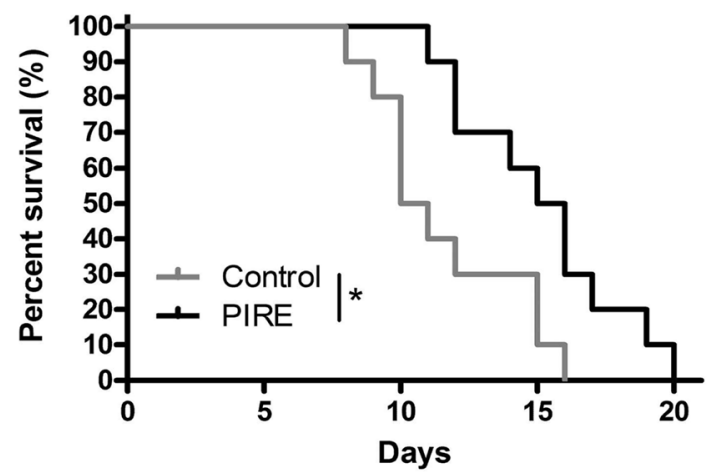

Fig. 1 Effect of plRE treatment on tumor growth and survival. C57BI/6 mice were intradermally injected with $0.5 \times 106$ B16F10-GFP tumor cells and treated with pIRE parameters: 10 square waved pulses of $1200 \mathrm{~V}$, duration $100 \mu \mathrm{s}$, frequency $1 \mathrm{kHz}$. Tumor volume was followed up every day (d) post treatments with a digital caliper and GFP expression was monitored in vivo. a Macroscopic visualization of tumor size and GFP expression following pIRE treatment. Scale bar represents $5 \mathrm{~mm}$. b Tumor growth representation of untreated tumors $(\Delta)$ and pIRE treated tumors (-). Values are means \pm SEM. ${ }^{* *} P<0.001$, (Two-way ANOVA analysis). c Kaplan-Meyer survival curve of untreated mice (gray line) and pIRE treated mice (black line). $N=10$ mice per group. $\left({ }^{*} P<0.05\right.$ (Log-rank (Mantel-Cox) Test)

2 days following the pulse delivery. Therefore, we tested the boosting effect of IL-12 cytokine expression on the antitumor immune response.
pIL-12 GET followed by pIRE induced tumor regression

We recently showed that IL-12 expression was significantly increased following GET protocol [34]. Here, we 


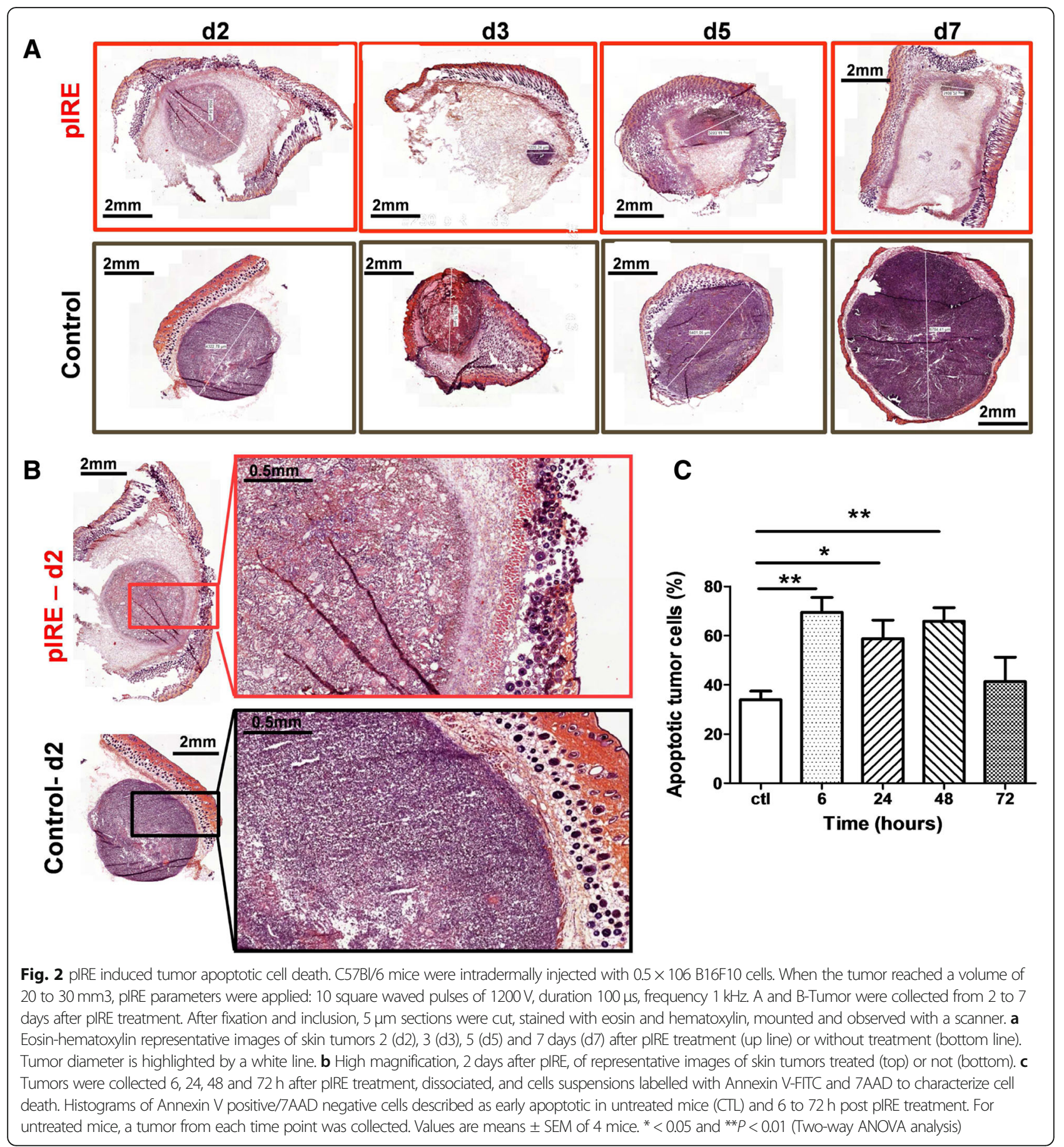

verified that IL-12 expression can induce IFN- $\gamma$ production (Fig. 3a). A significant amount of IFN- $\gamma$ was quantified locally, only when pIL-12 GET was performed and not in the untreated contralateral skin.

To test the efficacy of pIL-12 GET combined with pIRE pulses on regression of skin tumors, $\mathrm{C} 57 \mathrm{Bl} / 6$ mice were intradermally injected with $0.5 \times 10^{6}$ B16F10 cells. In absence of treatment, tumors grew quickly and all mice had to be sacrificed maximum 13 days after tumor induction
(Fig. 3b-d). One group of mice was treated with pIL-12 peritumoral GET which did not induce any significant difference on B16F10 tumor growth (Fig. 3b, c) or survival of mice (Fig. 3d) compared to untreated control mice. As we previously described, pIRE parameters induced a transient tumor shrinkage (Fig. 3b, c) and therefore an increase in survival of mice for up to 15 days compared to untreated animals (Fig. 3d). The last group of mice treated with pIL12 GET and 2 days later with pIRE displayed two different 

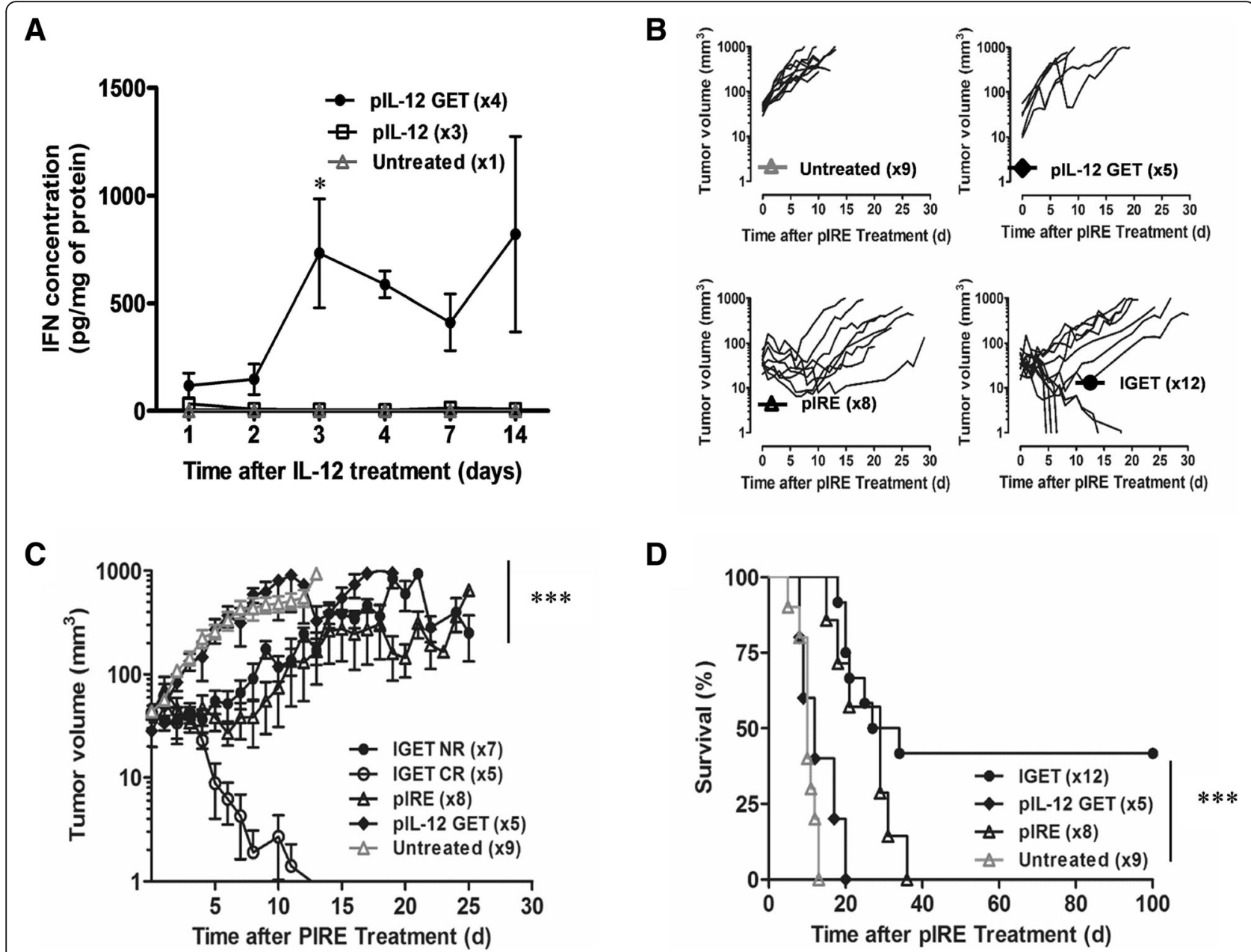

Fig. 3 IGET treatment induced partial B16F10 tumor regression. a CD11c-GFP-DTR mice were intradermally injected with $25 \mu \mathrm{g}$ of pIL-12 in $20 \mu \mathrm{l}$ PBS, or with $20 \mu \mathrm{l}$ of PBS alone in one flank and were submitted to GET protocol. The contralateral flank from IL-12 injected mice was non injected and non-pulsed to be used as an internal control. Mice were sacrificed from 1 to 14 days after treatment and skin from each flank were harvested and cultured overnight in complete medium $5 \% \mathrm{CO} 2,37^{\circ} \mathrm{C}$. IFN- $\gamma$ content was determined in the cultured supernatant of plL-12 treated skin (plL-12 GET), of plL-12 untreated skin (pIL-12) and of PBS treated skin (PBS GET) by ELISA. $3 \leq n \leq 4,2$ independent experiments, statistical analysis: 2 way Anova, ${ }^{*} p<0.05$. b CD11c-GFP-DTR mice were intradermally injected with $0.5 \times 106$ B16F10 cells. When the tumor reached a volume of 7 to $15 \mathrm{~mm} 3,2 \times 25 \mu \mathrm{g}$ of plL-12 were injected intradermally in the healthy skin directly surrounded the tumor. Electrotransfection was realized using GET protocol. Two days later, pIRE parameters were applied on previously treated tumors. Tumor volume was followed up to 100 days in case of complete regression. Individual curves are plotted for untreated control, pIL-12-GET alone, pIRE alone, and IGET treated mice. c Mean +/- SEM tumor growth progression while separating IGET treated group between complete regression group (CR) and non-responding group (NR). From day $4,{ }^{* * *} p<0.001$ between IGET CR and untreated or pIL-12-GET groups (Two-way ANOVA analysis). $\mathbf{d}$ Mice survival of untreated control, plL-12 GET, pIRE and IGET treated tumor. ${ }^{* * *} P<0.001$ (Log-rank (Mantel-Cox) Test) between untreated control, plL-12 GET, pIRE and IGET treated tumor ( $5 \leq n \leq 12,3$ independent experiments)

tumor behaviors. Seven out of 12 mice never rejected the tumor and displayed the same growth rate as PIRE treated mice (Fig. 3b, c). However, 5 out of 12 mice had totally rejected the tumor $(41.6 \%$ of complete regression) (Fig. 3b, c). This regression lasted for 100 days after treatment (Fig. 3d). One of the mouse needed to be sacrificed because of teeth malformation that could no longer be cured. Nevertheless, the combination of pIL-12 GET and pIRE not only enhanced survival but could bring a curative effect. This two-step treatment was named Immune-Gene Electro-Therapy (IGET).

\section{IGET induced memory immune response}

Mice with complete tumor regression were injected with $0.5 \times 10^{6}$ B16F10 cells, in the opposite flank to the first tumor, 100 days after the IGET treatment. Control naïve mice developed tumors in 3 to 5 days and all mice had to be sacrificed between 18 and 20 days after tumor induction (Fig. 4). Among the four challenged mice, 2 developed a tumor at the new site of implantation, but with a delay of 15 days compared with untreated mice (Fig. 4a). Interestingly, 2 out of 4 challenged mice never developed tumor up to 100 days after the second 
A

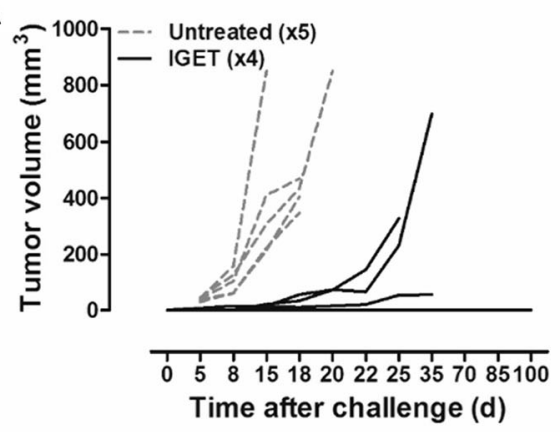

B

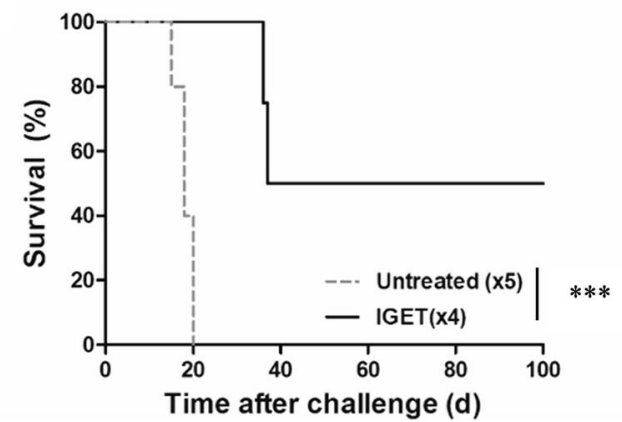

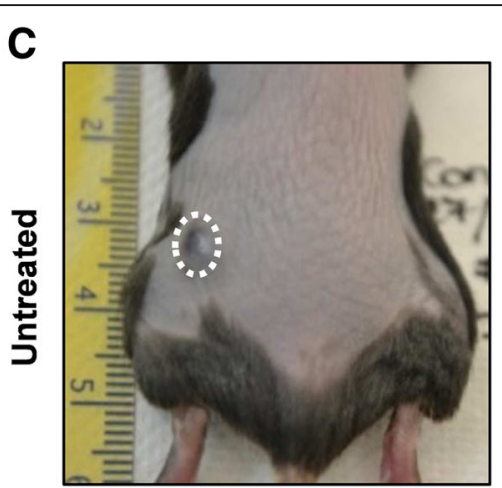

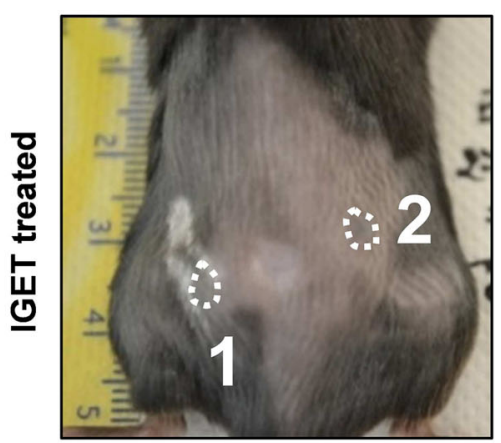

Fig. 4 IGET induced a memory immune response. Mice experiencing complete regression of the tumor 100 days after the first treatment were injected again with $0.5 \times 106$ B16F10 cells. Injection in naïve mice served as control (untreated). Tumor growth was followed up to 100 days. a In IGET treated group (black line), 2 mice developed the tumor, 1 needed to be sacrificed for external purpose, 2 mice never developed tumors. $\mathbf{b}$ Mice survival in untreated (dash gray line) and IGET treated group (black line), ${ }^{* * *} \mathrm{P}<0.001$ (Log-rank (Mantel-Cox) Test) (c) Pictures illustrating the position of injection sites and the absence of tumor development in an IGET mouse (bottom). $4 \leq N \leq 5$ mice per group

induction (Fig. 4). In conclusion, the IGET treatment induced a long-term memory immune response controlling the development of distant new tumors.

\section{IGET treatment slowed down distant tumor growth}

In the clinic, treated patients frequently have several nodules in the same area. We have previously demonstrated that the induced IL-12 production is specifically localized at the site of the electro-gene-transfer [34]. Therefore, to analyze the efficacy of the IGET on distant tumors, B6 mice were injected on both flanks with B16F10 cells. IGET was applied only on one developing tumor. As described in Fig. 3, two different behaviors were observed. $50 \%$ of the treated mice (9 out of 18) presented a tumor regression on the treated tumor, while the other $50 \%$ (9 out of 18) presented no tumor regression (Fig. 5a). The mice with regression were identified as responding mice and the others as non-responding mice. No regression of contralateral non-treated tumors was detected on responding or non-responding mice. Despite a non-statistically significant difference (Log-rank (Mantel-Cox) test; $p$ value $=0.0983$ ), we observed a slightly increased survival of responding mice compared to non-responding mice (median survival of 13 and 11 days respectively) (Fig. 5b). We attributed this result to a difference in growth rate of distant tumors. Therefore, we analyzed separately the growth rate of distant tumors from responding and non-responding mice by comparing the tau value of exponential growth regression curve associated to each group (Fig. 5c). The distant tumor tau value from responding mice $\left(3.907, \mathrm{R}^{2}=0.4687\right.$ ) was lower (about 56\%) than the one from non-responding mice $\left(6.899, R^{2}=0.8819\right)$. This result suggested a role of the immune system, modulated by IL-12 expression, controlling tumor development at the distant site.

\section{IGET induced tumor regression depended on adaptive immune response}

To analyze the putative role of the immune system in the tumor growth control, IGET protocol was applied to nude immunodeficient mice implanted with $0.5 \times 10^{6}$ B16F10 cells. Both pIRE and IGET treated mice presented a transient regression of tumor volume (Fig. 6a). But importantly, no complete regression could be observed among IGET treated nude mice (Fig. 6a) contrary to WT mice (Fig. 3b, c) suggesting an implication of the adaptive immune system. Nevertheless, IGET treated tumors in nude mice presented a slower growth rate than 

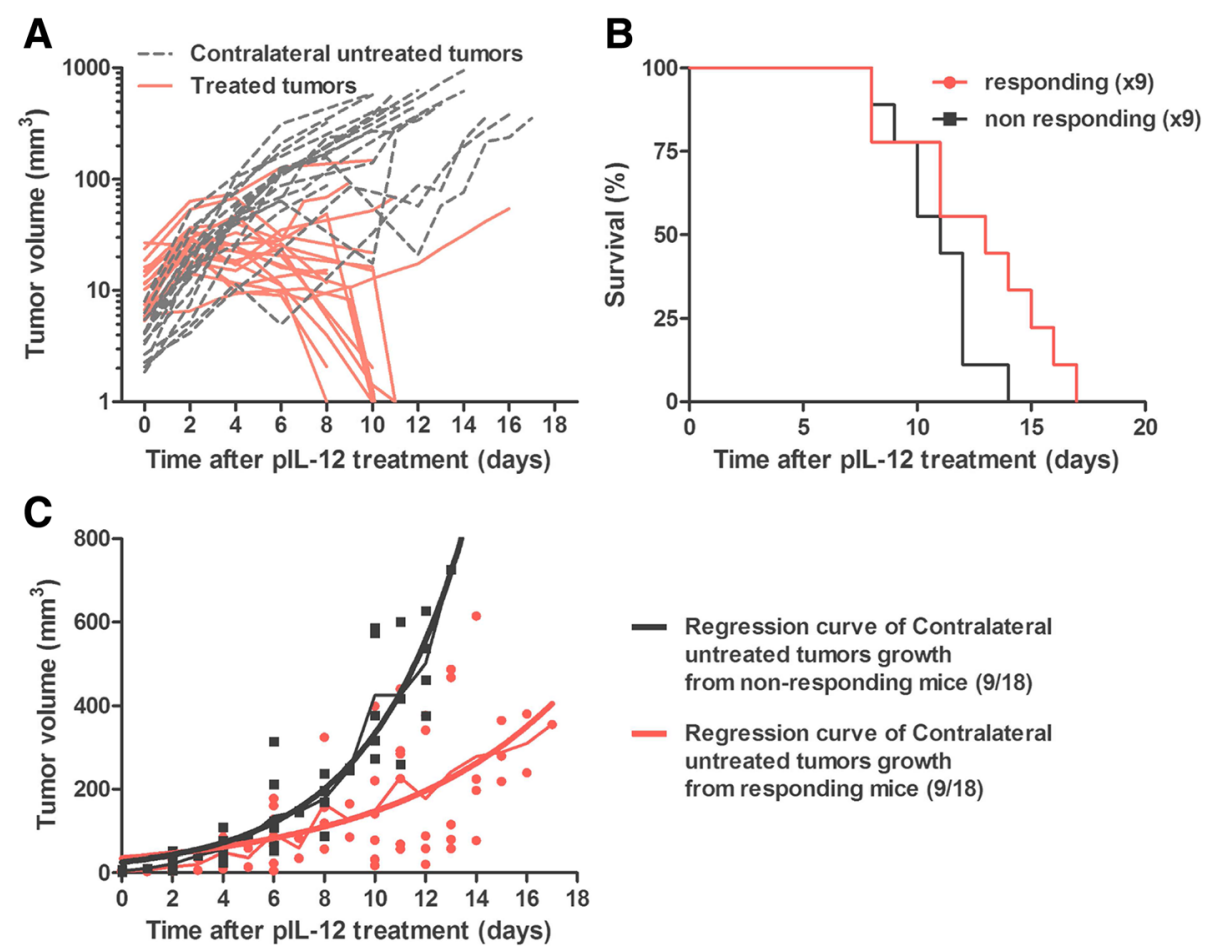

Fig. 5 IGET treatment slowed down distant tumor growth. CD11c-GFP-DTR mice were intradermally injected with $0.5 \times 106$ B16F10 cells in both flanks. When one of the tumors reached a volume of 7 to $15 \mathrm{~mm} 3,2 \times 25 \mu \mathrm{g}$ of plL-12 were injected intradermally in the healthy skin directly surrounding the tumor. Electrotransfection was realized using HV-MV electrical parameters. Two days later, pIRE parameters were applied on previously treated tumor. a The volume of treated (red) and untreated (black) tumors was measured until one of the tumor reached $1200 \mathrm{~mm} 3$. As described previously treated tumors can be divided in responders (rejection of the treated tumor) and non-responders (no rejection of the treated tumor), (b) Survival curves of responding and non-responding mice and (c) growth curves of untreated tumors from responding mice (red) and non-responding mice (Black). Dots represents individual points; thin lines, the median of tumor growth; thick lines, the calculated regression curves. $N=18,2$ independent experiments

pIRE treated or untreated mice resulting in increased survival (Fig. 6b). This result suggested an implication of other mechanisms controlling tumor growth. Despite that, all (14 out of 14) IGET treated nude mice were sacrificed between 15 and 22 days after treatment compared to $42 \%$ of complete regression in WT mice.

\section{IGET induced tumor rejection implicated innate immunity}

In this protocol, naked DNA was injected intradermally before pIRE was applied. Internalized naked DNA recognized by the Toll Like Receptor 9 (TLR9) can directly activate immune cells. We used CpG free constructions to avoid this problem. Nevertheless to understand whether the positive effect observed with this treatment implicated a bystander effect by the introduction of foreign DNA, $\mathrm{TLR}^{-1-}$ mice were intradermally injected with $0.5 \times 10^{6}$ B16F10 cells and then submitted to IGET. Interestingly, $\mathrm{TLR9}^{-/-}$mice resumed the bimodal response observed in WT mice (Fig. 6). Among IGET treated TLR9 ${ }^{-1-}$ mice, 4 out of $16(25 \%)$ experienced a complete regression lasting 100 days after the treatment (Fig. 6c, d).
In conclusion, even though the efficacy of the treatment was reduced in mice with an impaired innate immunity, it appeared that the positive effect obtained with IGET treatment implicated involvement of other mechanisms not only the recognition of naked pDNA by innate receptors.

\section{Toxicity of the pIL-12 GET}

The analysis of hematological parameters showed no difference between control groups and GET groups for male and female mice at D49. Few differences were observed at D15, probably due to sample coagulation but not to a toxicity of the treatment (Table 1).

The analysis of biochemistry parameters revealed no difference between control group and GET group for male and female mice at D15 and at D49 (See Additional file 5: Table S1).

Anatomopathology results were the final observations. In treated mice euthanized on day 15 , diffuse chronic dermal inflammation was observed in the skin. It affected $3 / 3$ males, with a moderate severity, and $4 / 4$ females with a marked severity. Controls were not affected. On day 49, 1/2 control 


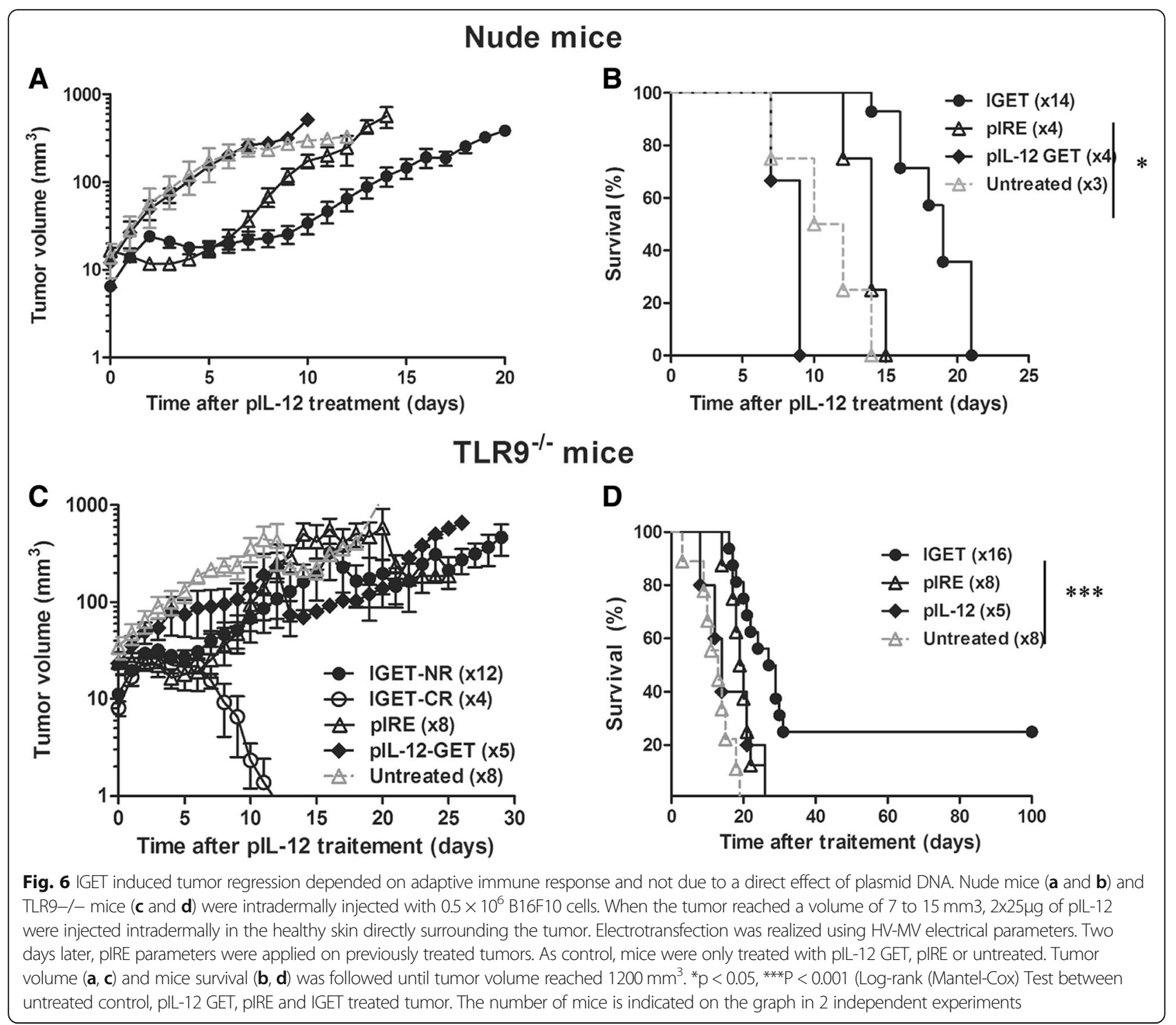

males also presented dermal inflammation with a minimal severity. 3/4 treated males were affected, with a slight or moderate severity, while $2 / 4$ treated females were also affected, with a minimal or moderate severity. Altogether, this indicated that GET induced inflammation in the dermis, which tended to disappear over time (partial recovery within 50 days). There were no systemic change related to GET at any time point. All observations were spontaneous. Under the conditions of this experiment, a single intradermal injection and skin electrotransfer administration of the $\mathrm{CpG}$ free construct to mice induced inflammatory changes in the skin that tended to regress over time (partial recovery).

\section{Discussion}

In this study, we showed that peritumoral plasmid IL-12 electrotransfer followed with partially Irreversible
Electropermeabilization (IGET) induced tumor regression in a mouse model of melanoma correlating with a local secretion of IL-12 [34] and IFN- $\gamma$. This treatment induced a systemic activation of the adaptive immune system leading to a growth delay of distant tumors and to the development of an immune memory that protected against the emergence of a second tumor.

When peritumoral GET of plasmid IL-12 alone was performed, we did not observe any tumor regression. Complete regression $(42 \%)$ of treated tumors was observed when IL-12 GET was associated with pIRE treatment. This result could be due to the fact that peritumoral IL-12 GET did not impact the integrity of the tumor structure. The B16F10 melanoma model is a low immunogenic tumor model with low tumor-antigen spreading. Under our protocol IL-12 secretion by transfected cells failed to activate immune cells for which the 
Table 1 Hematology analysis of male and female mice of both groups at D15 and D49

\begin{tabular}{|c|c|c|c|c|c|}
\hline \multirow[t]{2}{*}{ Female mice } & & \multicolumn{2}{|l|}{ D15 } & \multicolumn{2}{|l|}{ D49 } \\
\hline & & Group 1 & Group 2 & Group 1 & Group 2 \\
\hline Parameters & Unity & Control & EGT & Control & EGT \\
\hline White blood cells & $10 \wedge 3 / \mu l$ & $6.4 \pm 1.7$ & $2.9 \pm 1.5$ & $7.7 \pm 2.1$ & $6.3 \pm 1.0$ \\
\hline hemoglobin & $\mathrm{g} / \mathrm{dl}$ & $13.0 \pm 0.3$ & $10.9 \pm 3.5$ & $13.8 \pm 1.1$ & $14.0 \pm 1.3$ \\
\hline Red blood cells & $10 \wedge 6 / \mu l$ & $5.5 \pm 3.2$ & $6.7 \pm 2.1$ & $8.4 \pm 0.8$ & $8.4 \pm 0.7$ \\
\hline Hematocrit & $\%$ & $26.6 \pm 15.3$ & $32.9 \pm 11.6$ & $40.6 \pm 4.2$ & $40.8 \pm 3.9$ \\
\hline Mean corpuscular volume & $\mathrm{fl}$ & $48.7 \pm 0.2$ & $48.5 \pm 2.6$ & $48.3 \pm 0.3$ & $48.4 \pm 0.7$ \\
\hline Platelets & $10 \wedge 3 / \mu l$ & $333 \pm 180$ & $536 \pm 297$ & $376 \pm 6$ & $373.8 \pm 62.5$ \\
\hline Mean corpuscular hemoglobin & $\mathrm{pg}$ & $28.3 \pm 16.0$ & $16.2 \pm 1.5$ & $16.4 \pm 0.3$ & $16.5 \pm 0.3$ \\
\hline Mean corpuscular hemoglobin concentration & $\mathrm{g} / \mathrm{dl}$ & $58.4 \pm 32.7$ & $33.6 \pm 4.0$ & $34.0 \pm 0.7$ & $34.2 \pm 0.1$ \\
\hline \multirow[t]{2}{*}{ Male mice } & & \multicolumn{2}{|l|}{ D15 } & \multicolumn{2}{|l|}{ D49 } \\
\hline & & Group 1 & Group 2 & Group 1 & Group 2 \\
\hline Parameters & Unity & Control & EGT & Control & EGT \\
\hline White blood cells & $10 \wedge 3 / \mu l$ & $5.6 \pm 2.3$ & $8.0 \pm 1.9$ & $8.4 \pm 0.1$ & $7.5 \pm 3.4$ \\
\hline hemoglobin & $g / d l$ & $13.0 \pm 2.5$ & $14.9 \pm 1.0$ & $13.9 \pm 1.4$ & $13.2 \pm 0.7$ \\
\hline Red blood cells & $10 \wedge 6 / \mu l$ & $7.6 \pm 1.5$ & $8.6 \pm 0.6$ & $8.3 \pm 1.1$ & $8.0 \pm 0.3$ \\
\hline Hematocrit & $\%$ & $36.8 \pm 7.3$ & $42.5 \pm 1.9$ & $40.9 \pm 3.5$ & $38.7 \pm 1.3$ \\
\hline Mean corpuscular volume & $\mathrm{fl}$ & $48.5 \pm 0.1$ & $49.6 \pm 1.2$ & $49.6 \pm 2.6$ & $48.3 \pm 0.6$ \\
\hline Platelets & $10 \wedge 3 / \mu l$ & $351 \pm 6$ & $345 \pm 112$ & $424 \pm 62$ & $368 \pm 61$ \\
\hline Mean corpuscular hemoglobin & $\mathrm{pg}$ & $17.0 \pm 0.1$ & $17.3 \pm 0.4$ & $16.8 \pm 0.6$ & $16.4 \pm 0.3$ \\
\hline Mean corpuscular hemoglobin concentration & $\mathrm{g} / \mathrm{dl}$ & $35.2 \pm 0.3$ & $34.9 \pm 1.1$ & $34.0 \pm 0.6$ & $34.0 \pm 1.1$ \\
\hline
\end{tabular}

contact with tumor antigens was limited. In contrast, the application of pIRE treatment, inducing destruction of tumor cells, may release tumor antigens and alarmines, danger signals released by necrotic and apoptotic cells known to activate the immune system [27, 28, 38]. In this situation, IL-12 secreted by transfected peritumoral skin cells boosted the activation of skin immune cells initiated by alarmines and recognition of tumor antigens. The efficacy of intratumoral and peritumoral IL-12 electrotransfection has been compared in a murine model of sarcoma using plate electrodes [9]. In this study, intratumoral GET induced $90 \%$ of complete regression whereas peritumoral GET induced $20 \%$ of complete regression. The type of tumor (sarcoma vs melanoma) and the distance of the peritumoral treatment to the tumor could be the reason for the difference compared to our results [6]. The same authors also demonstrated, in a mouse model of metastatic melanoma, that intramuscular electrotransfection of a plasmid encoding the integrin receptor antagonist AMEP is inefficient compared to the very efficient tumoral electrotransfection [39]. They also showed the inefficiency of intramuscular IL-12 GET alone to induce regression of a mouse model of sarcoma [9]. In this model, a positive effect of IL-12 GET was observed only when several treatments were performed combined with intratumoral electrochemotherapy (ECT).

Shirley et al. performed an impressive comparative work [40]. They not only compared the efficiency of 3 different electrical protocols but they also compared 2 different electrodes, caliper and peritumoral needles, on the transfection efficiency of a common (pUMC3-mIL12) and an optimized (pAG250) IL-12 plasmid known to induce a higher production of IL-12. Tumors received three deliveries of pDNA on days 0,4 and 7 , while only one single pIL-12 GET was applied in the present study. The protocol bringing the highest level of IL-12 expression was highly destructive for the tumor. Shirley et al. further demonstrated that the dose of secreted IL-12 was determinant for the anti-tumor efficacy of the treatment, i.e., a lower dose of IL-12 had a more efficient anti-tumor effect than a higher dose. Interestingly, 100\% of complete regression was obtained with one of the 
strongest electric fields applied with needle electrodes inducing important cellular damages and the lowest IL12 production compared with the effect obtained with the other electrical parameters. By comparing studies using IL-12 GET with intratumoral, peritumoral or intramuscular injection, it appeared that, in all cases, loss of the tumor integrity was necessary to obtain an efficient action of IL-12. In our study, this was observed with the application of pIRE 2 days after IL-12 GET. In the case of intramuscular injection, this effect was obtained with the associated ECT [9]. When the IL-12 GET was performed with intratumoral injection, Shirley et al. demonstrated that the use of peritumoral needle electrodes induced local tumor damage that was equivalent to the damage obtained with pIRE treatment. Thus, our two-step modality treatment allowed us to decipher the mechanisms that might be implicated in tumor regression induced by intratumoral injection: first, the release of tumor antigens and danger signals by lysed tumor cells, and second, the full activation of several subtypes of immune cells by IL-12 secreted by transfected skin cells.

Under the conditions of this experiment, no toxicity of treatment was noted through hematology and biochemistry analyses for male or female mice at D15 and D49. A single intradermal injection and skin electrotransfer of the $\mathrm{CpG}$ free construct induced inflammatory changes in the skin that tended to regress over time (partial recovery). Similar observations were obtained by other groups using different plasmids and electrical pulsing parameters [41, 42].

The efficacy of IL-12 GET, whatever the site of injection, was also dependent on the number of treatments. With only one IL-12 GET and one pIRE treatment, we obtained $42 \%$ of complete regression whereas the $100 \%$ obtained in the study of Shirley et al. with peritumoral needle electrodes required 3 successive treatments [40]. Based on these results, we could further optimize the number of treatments in order to increase the efficacy of our protocol.

One of the challenges of immune therapies is to induce an efficient memory immune response. Our results showed that $50 \%$ of cured mice after IGET treatment were protected from the development of a new tumor. This was consistent with results obtained in different tumor models with different sites of injection $[9,40,43]$. A memory immune response was induced only when adaptive immune cells were activated. Treatment of nude mice showed that these T-cell-deficient mice were not able to reject the tumor, supporting the full dependence of IGET treatment efficacy on T cell activation. Nevertheless, after day 6, a sustained delay in tumor growth of IGET treated tumors was observed compared with pIRE only treated tumors. This delay could be explained by the role of IL-12 on innate immune cells. A role for natural killer (NK) cells was previously suggested [40]. Another potentially involved innate $\mathrm{T}$ cell population was the invariant Natural Killer T (iNKT) cell population [44-46]. These cells were specific for lipid antigens presented by the non-classical MHC molecule CD1d. iNKT cells were defined as fast producers of large amounts of IFN- $\gamma$ in the hours after stimulation either directly by antigens or after interaction with APCs. Moreover, nude mice were deficient in $\mathrm{T}$ cells but not in B cells, and it was known that Ig production influences tumor growth $[47,48]$.

Another challenge of immune therapies was the induction of systemic effects in order to eliminate metastasis as well as treated tumors. Although the present single shot IGET treatment did not induce complete regression of distant tumors, their growth rate was reduced compared with untreated tumors. This observation also suggested a systemic activation of the immune system. Therefore, one could hypothesize that the electric field activated skin dendritic cells that, as a result, became more sensitive to IL-12 and more efficient in the capture of tumor antigens. Clinical development of IL-12 GET have been reported either on human $[8,49]$ and veterinarian $[14,50]$ applications.

Moreover, it was shown, using different electrical parameters and devices, that epidermal dendritic cells could be electrotransfected in vivo with plasmids encoding the GFP [51] or viral peptides and then migrated to the draining lymph node [52].

\section{Conclusions}

Our approach appeared of interest when irreversible electropermeabilization did not bring a complete eradication of the tumor, to boost the immune system and eradicate remaining tumor cells that were not affected or were reversibly electropermeabilized. Our findings showed that IGET treatment could induce a systemic and long-lasting immunity resulting in complete regression of melanoma in mice.

This two-step procedure allowed us to further distinguish the impact of pIL-12 skin electrotransfection on one hand and of the electropermeabilized tumor on the other hand on the activation of the immune system. Therefore, our study pointed out that tumor disruption and release of tumor antigens were essential to obtain an efficient activation of the adaptive immune system. This was a hidden aspect of the protocol with peritumoral needle electrodes. Although the level and the lifetime of expression of IL-12, i.e., number of treatments, need to be optimized, IGET is a promising treatment to be transposed to a human clinic. 


\section{Additional files}

Additional file 1: Figure S1. Partial Irreversible electropermeabilization (pIRE) procedure. (DOCX $285 \mathrm{~kb})$

Additional file 2: Figure S2. Optimization of the delay between GeneElectro-Transfer procedure and pIRE treatment. (DOCX $145 \mathrm{~kb}$ )

Additional file 3: Figure S3. Effect of pIRE treatment on tumor volume and survival on transgenic mice. (DOCX $290 \mathrm{~kb}$ )

Additional file 4: Figure S4. Effect of Hsp70 induction of plRE treatment (DOCX $427 \mathrm{~kb}$ )

Additional file 5: Table S1. Biochemistry results of male and female mice of both groups at D15 and D49, mean \pm SD. (DOCX $16 \mathrm{~kb}$ )

\begin{abstract}
Abbreviations
CD4: Cluster of differentiation 4; CTL: Cytotoxic T lymphocytes; CTLA4: Cytotoxic T-lymphocyte-associated protein 4; DC: Dendritic cells: EP: Electro-permeabilization; GET: Gene Electro-Transfer; Hsp70: Heat-shock protein 70; HV-MV: High voltage-Medium voltage; IGET: Immune-Gene Electro-Therapy; IL-12: Interleukine-12; INF- : Gamma-interferon; NK: Natural killer; PD1: Programmed cell death protein 1; PDL-1: Programmed deathligand 1; PEF: Pulsed electric field; pIRE: Partial irreversible electroporation; Th1: Helper T cell Type1
\end{abstract}

\section{Acknowledgements}

The authors want to thank Erick Phonesouk for his technical assistance and Dr. Franck Couillaud for the generous gift of transgenic hspluc70: NLF1 mice. We thank the "Toulouse Réseau Imagerie" and Anexplo core IPBS facilities (Genotoul, Toulouse, France). Research was conducted in the scope of the EBAM European Associated Laboratory (LEA) and resulted from the networking efforts of the COST Action TD1 104 (http://www.electroporation.net).

\section{Authors' contributions}

Data collection by LP, EB, SC, MB and MG. Data analysis by LP, EB, SC, MB, MPR, JT and MG, Writing and study design by LP, JT and MG. All authors read and approved final manuscript.

\section{Funding}

This study was supported by institutional grants of the National Institute for Cancer Research (INCA \# 2014-177), the Region Midi-Pyrénées (recherche en transfert clinique, normalisation, et innovation interdisciplinaire en biosanté $n^{\circ} 11052700$ et $n^{\circ} 13050740$ ) and ITMO Cancer AVIESAN (National Alliance for life sciences and Healt) with the frame work of the cancer Plan NUMEP (PC201615).

\section{Availability of data and materials}

The datasets analyzed during the current study are available from the corresponding author on request.

\section{Ethics approval and consent to participate \\ N/A}

\section{Consent for publication}

N/A

\section{Competing interests}

No non-financial conflicts of interest exist for any of the authors.

Received: 6 February 2019 Accepted: 13 June 2019

Published online: 26 June 2019

\section{References}

1. Callahan MK, Flaherty CR, Postow MA. Checkpoint blockade for the treatment of advanced melanoma. Cancer Treat Res. 2016:231-50.

2. Trinchieri G. Interleukin-12 and the regulation of innate resistance and adaptive immunity. Nat Rev Immunol. 2003;3:133-46.

3. Leonard JP, Sherman ML, Fisher GL, Buchanan $\perp$, Larsen G, Atkins MB, Sosman JA, Dutcher JP, Vogelzang NJ, Ryan JL. Effects of single-dose interleukin-12 exposure on interleukin-12-associated toxicity and interferongamma production. Blood. 1997;90:2541-8.
4. Heller R, Lundberg CM, Burcus N, Edelblute C, Guo SQ. Gene electrotransfer of plasmids encoding cytokines as an effective immunotherapy approach for melanoma. J Immunol. 2016;196:213-6.

5. Rols MP, Delteil C, Golzio M, Dumond P, Cros S, Teissie J. In vivo electrically mediated protein and gene transfer in murine melanoma. Nat Biotechnol. 1998:16:168-71.

6. Kamensek U, Cemazar M, Tratar UL, Ursic K, Sersa G. Antitumor in situ vaccination effect of TNF alpha and IL-12 plasmid DNA electrotransfer in a murine melanoma model. Cancer Immunol Immun. 2018;67:785-95.

7. Golzio M, Teissie J, Rols MP. Direct visualization at the single-cell level of electrically mediated gene delivery. Proc Natl Acad Sci U S A. 2002; 99:1292-7.

8. Daud Al, DeConti RC, Andrews S, Urbas P, Riker Al, Sondak VK, Munster PN, Sullivan DM, Ugen KE, Messina JL, Heller R. Phase I trial of Interleukin-12 plasmid electroporation in patients with metastatic melanoma. J Clin Oncol. 2008;26:5896-903

9. Pavlin D, Cemazar M, Kamensek U, Tozon N, Pogacnik A, Sersa G. Local and systemic antitumor effect of intratumoral and peritumoral IL-12 electrogene therapy on murine sarcoma. Cancer Biol Ther. 2009:8:2114-22.

10. Cemazar M, Avgustin JA, Pavlin D, Sersa G, Poli A, Levacic AK, Tesic N, Tratar UL, Rak M, Tozon N. Efficacy and safety of electrochemotherapy combined with peritumoral IL-12 gene electrotransfer of canine mast cell tumours. Vet Comp Oncol. 2017;15:641-54

11. Calvet CY, Famin D, Andre FM, Mir LM. Electrochemotherapy with bleomycin induces hallmarks of immunogenic cell death in murine colon cancer cells. Oncoimmunology. 2014;3:e28131.

12. Nuccitelli R, McDaniel A, Anand S, Cha J, Mallon Z, Berridge JC, Uecker D. Nano-pulse stimulation is a physical modality that can trigger immunogenic tumor cell death. J Immunother Cancer. 2017;5:32.

13. Kishida T, Asada H, Itokawa Y, Yasutomi K, Shin-ya M, Gojo S, Cui F, Ueda Y, Yamagishi H, Imanishi J, Mazda O. Electrochemo-gene therapy of cancer: Intratumoral delivery of interleukin-12 gene and bleomycin synergistically induced therapeutic immunity and suppressed subcutaneous and metastatic melanomas in mice. Mol Ther. 2003;8:738-45.

14. Salvadori C, Svara T, Rocchigiani G, Millanta F, Pavlin D, Cemazar M, Tratar UL, Sersa G, Tozon N, Poli A. Effects of electrochemotherapy with cisplatin and peritumoral IL-12 gene electrotransfer on canine mast cell tumors: a histopathologic and immunohistochemical study. Radiol Oncol. 2017;51: 286-94

15. Torrero MN, Henk WG, Li SL. Regression of high-grade malignancy in mice by bleomycin and interleukin-12 electrochemogenetherapy. Clin Cancer Res. 2006;12:257-63.

16. Davalos R, Huang Y, Rubinsky B. Electroporation: bio-electrochemical mass transfer at the nano scale. Microscale Therm Eng. 2000:4:147-59.

17. Rubinsky B, Onik G, Mikus P. Irreversible electroporation: a new ablation modality - clinical implications. Technol Cancer Res Treat. 2007;6:37-48.

18. Davalos RV, Mir LM, Rubinsky B. Tissue ablation with irreversible electroporation. Ann Biomed Eng. 2005;33:223-31.

19. Thomson KR, Kavnoudias H, Neal RE. Introduction to irreversible electroporation--principles and techniques. Tech Vasc Interv Radiol. 2015;18: 128-34.

20. Al-Sakere B, Andre F, Bernat C, Connault E, Opolon P, Davalos RV, Rubinsky B, Mir LM. Tumor ablation with irreversible electroporation. PLoS One. 2007; 2:e1135.

21. Lee EW, Wong D, Prikhodko SV, Perez A, Tran C, Loh CT, Kee ST. Electron microscopic demonstration and evaluation of irreversible electroporationinduced Nanopores on hepatocyte membranes. J Vasc Interv Radiol. 2012; 23:107-13.

22. Neal RE, Rossmeisl JH, D'Alfonso V, Robertson JL, Garcia PA, Elankumaran S, Davalos RV. In vitro and numerical support for combinatorial irreversible electroporation and Electrochemotherapy glioma treatment. Ann Biomed Eng. 2014;42:475-87.

23. Ben-David E, Ahmed M, Faroja M, Moussa M, Wandel A, Sosna J, Appelbaum L, Nissenbaum I, Goldberg SN. Irreversible electroporation: treatment effect is susceptible to local environment and tissue properties. Radiology. 2013;269:738-47.

24. Dunki-Jacobs EM, Philips P, Martin RCG. Evaluation of thermal injury to liver, pancreas and kidney during irreversible electroporation in an in vivo experimental model. Brit J Surg. 2014;101:1113-21.

25. Deodhar A, Monette S, Single GW, Hamilton WC, Thornton RH, Sofocleous $\mathrm{CT}$, Maybody M, Solomon SB. Percutaneous irreversible electroporation lung 
ablation: preliminary results in a porcine model. Cardiovasc Inter Rad. 2011; 34:1278-87.

26. Jose A, Sobrevals L, Ivorra A, Fillat C. Irreversible electroporation shows efficacy against pancreatic carcinoma without systemic toxicity in mouse models. Cancer Lett. 2012;317:16-23.

27. Li XX, Xu K, Li W, Qiu XC, Ma BA, Fan QY, Li Z. Immunologic response to tumor ablation with irreversible electroporation. PLoS One. 2012;7:e48749.

28. Neal RE, Rossmeisl JH, Robertson JL, Arena CB, Davis EM, Singh RN, Stallings J, Davalos RV. Improved local and systemic anti-tumor efficacy for irreversible electroporation in immunocompetent versus Immunodeficient mice. PLoS One. 2013;8:e64559.

29. Heller R, Teissie J, Rols MP, Gehl J, Sersa G. Medical Applications Bioelectrics. 2017; Chapter 5 .

30. Kim HB, Sung CK, Baik KY, Moon KW, Kim HS, Yi JH, Jung JH, Moon MH, Choi OK. Changes of apoptosis in tumor tissues with time after irreversible electroporation. Biochem Biophys Res Commun. 2013;435:651-6.

31. Lee EW, Chen C, Prieto VE, Dry SM, Loh CT, Kee ST. Advanced hepatic ablation technique for creating complete cell death : irreversible electroporation. Radiology. 2010;255:426-33.

32. Garcia PA, Davalos RV, Miklavcic D. A numerical investigation of the electric and thermal cell kill distributions in electroporation-based therapies in tissue. PLoS One. 2014;9:e103083.

33. Davalos RV, Bhonsle S, Neal RE. Implications and considerations of thermal effects when applying irreversible electroporation tissue ablation therapy. Prostate. 2015;75:1114-8.

34. Pasquet L, Chabot S, Bellard E, Markelc B, Rols MP, Reynes JP, Tiraby G, Couillaud F, Teissie J, Golzio M. Safe and efficient novel approach for noninvasive gene electrotransfer to skin. Sci Rep. 2018;8:16833.

35. Golzio M, Mazzolini L, Ledoux A, Paganin A, Izard M, Hellaudais L, Bieth A, Pillaire MJ, Cazaux C, Hoffmann JS, Couderc B, Teissie J. In vivo gene silencing in solid tumors by targeted electrically mediated siRNA delivery. Gene Ther. 2007:14:752-9.

36. Fortin PY, Genevois C, Chapolard M, Santalucia T, Planas AM, Couillaud F. Dual-reporter in vivo imaging of transient and inducible heat-shock promoter activation. Biomed Opt Express. 2014;5:457-67.

37. Miklavcic D, Pucihar G, Pavlovec M, Ribaric S, Mali M, Macek-Lebar A Petkovsek M, Nastran J, Kranjc S, Cemazar M, Sersa G. The effect of high frequency electric pulses on muscle contractions and antitumor efficiency in vivo for a potential use in clinical electrochemotherapy. Bioelectrochemistry. 2005;65:121-8.

38. Calvet $C Y$, Mir $L M$. The promising alliance of anti-cancer electrochemotherapy with immunotherapy. Cancer Metast Rev. 2016;35: 165-77.

39. Bosnjak M, Dolinsek T, Cemazar M, Kranjc S, Blagus T, Markelc B, Stimac M, Zavrsnik J, Kamensek U, Heller L, Bouquet C, Turk B, Sersa G. Gene electrotransfer of plasmid AMEP, an integrin-targeted therapy, has antitumor and antiangiogenic action in murine B16 melanoma. Gene Ther. 2015;22:578-90.

40. Shirley SA, Lundberg CG, Li FY, Burcus N, Heller R. Controlled gene delivery can enhance therapeutic outcome for Cancer immune therapy for melanoma. Curr Gene Ther. 2015;15:32-43,

41. Heller L, Merkler K, Westover J, Cruz Y, Coppola D, Benson K, Daud A, Heller R. Evaluation of toxicity following electrically mediated interleukin-12 gene delivery in a B16 mouse melanoma model. Clin Cancer Res. 2006;12:3177-83.

42. Reed SD, Li S. Pre-clinical toxicity assessment of tumor-targeted interleukin12 low-intensity electrogenetherapy. Cancer Gene Ther. 2011;18:265-74.

43. Li SL, Zhang XJ, Xia XQ. Regression of tumor growth and induction of longterm antitumor memory by interleukin 12 electro-gene therapy. J Nat Cancer Inst. 2002;94:762-8.

44. Bendelac A, Killeen N, Littman DR, Schwartz RH. A subset of Cd4(+) Thymocytes selected by Mhc class-I molecules. Science. 1994;263:1774-8.

45. Bendelac A, Lantz O, Quimby ME, Yewdell JW, Bennink JR, Brutkiewicz RR. Cd1 recognition by mouse Nk1(+) T-lymphocytes. Science. 1995;268:863-5.

46. Terabe M, Berzofsky JA. The role of NKT cells in tumor immunity. Adv Cancer Res. 2008:101:277-348.

47. Carnaud C, Lee D, Donnars O, Park SH, Beavis A, Koezuka Y, Bendelac A. Cutting edge: cross-talk between cells of the innate immune system: NKT cells rapidly activate NK cells. J Immunol. 1999;163:4647-50.

48. Eberl G, MacDonald HR. Selective induction of NK cell proliferation and cytotoxicity by activated NKT cells. Eur J Immunol. 2000;30:985-92.
49. Canton DA, Shirley S, Wright J, Connolly R, Burkart C, Mukhopadhyay A, Twitty C, Qattan KE, Campbell JS, Le MH, Pierce RH, Gargosky S, Daud A Algazi A. Melanoma treatment with intratumoral electroporation of tavokinogene telseplasmid (pIL-12, tavokinogene telseplasmid). Immunotherapy. 2017;9:1309-21.

50. Pavlin D, Cemazar M, Cor A, Sersa G, Pogacnik A, Tozon N. Electrogene therapy with interleukin-12 in canine mast cell tumors. Radiol Oncol. 2011; 45:31-9.

51. Amante DH, Smith TRF, Kiosses BB, Sardesai NY, Humeau LMPF, Broderick KE. Direct transfection of dendritic cells in the epidermis after plasmid delivery enhanced by surface electroporation. Hum Gene Ther Method. 2014;25:315-6.

52. Smith TRF, Schultheis $K$, Kiosses WB, Amante DH, Mendoza JM, Stone JC, McCoy JR, Sardesai NY, Broderick KE. DNA vaccination strategy targets epidermal dendritic cells, initiating their migration and induction of a host immune response. Mol Ther Methods Clin Dev. 2014;1.

\section{Publisher's Note}

Springer Nature remains neutral with regard to jurisdictional claims in published maps and institutional affiliations.

Ready to submit your research? Choose BMC and benefit from:

- fast, convenient online submission

- thorough peer review by experienced researchers in your field

- rapid publication on acceptance

- support for research data, including large and complex data types

- gold Open Access which fosters wider collaboration and increased citations

- maximum visibility for your research: over $100 \mathrm{M}$ website views per year

At $\mathrm{BMC}$, research is always in progress.

Learn more biomedcentral.com/submissions 